\title{
Chronic Neurotrophin-3 Strengthens Synaptic Connections to Motoneurons in the Neonatal Rat
}

\author{
Victor L. Arvanian, ${ }^{1}$ Philip J. Horner, ${ }^{2}$ Fred H. Gage, ${ }^{3}$ and Lorne M. Mendell ${ }^{1}$ \\ ${ }^{1}$ Department of Neurobiology and Behavior, State University of New York at Stony Brook, Stony Brook, New York 11794, ${ }^{2}$ Department of Neurological \\ Surgery, University of Washington, Seattle, Washington 98104, and '3aboratory of Genetics, The Salk Institute, La Jolla, California 92161
}

We report that neurotrophin-3 (NT-3), delivered chronically via fibroblasts implanted intrathecally into neonatal rats, can facilitate synaptic transmission in the spinal cord. A small collagen plug containing NT-3-secreting fibroblasts was placed on the exposed dorsal surface of the spinal cord (L1) of 2-d-old rats; controls received $\beta$-galactosidase-secreting fibroblasts. After $6 \mathrm{hr}$ to $12 \mathrm{~d}$ of survival, synaptic potentials (EPSP) elicited by two synaptic inputs, L5 dorsal root and ventrolateral funiculus (VLF), were recorded intracellularly in L5 motoneurons in vitro. Preparations treated with NT-3 implants exhibited enhanced monosynaptic synaptic transmission from both inputs, which persisted over the entire testing period. Unlike acute enhancement of transmission by NT-3 (Arvanian and Mendell, 2001a), the chronic effect could occur at connections not normally eliciting an NMDA receptor-mediated response at the time of NT-3 exposure. Using susceptibility to blockade of the NMDA receptor by $\mathrm{Mg}^{2+}$ and APV, we confirmed that chronic treatment with NT-3 did not enhance NMDA receptor activity at these connections. Cords treated with chronic NT-3 also transiently displayed polysynaptic components activated by VLF that were blocked by the NMDA receptor antagonist APV. These novel NMDA receptor-mediated potentials may reflect changes in interneurons near the site of fibroblast implantation. We conclude that chronic NT-3 enhances the potency of segmental and descending projections via mechanisms different from those underlying acute changes.

Key words: neurotrophin; NT-3; genetically engineered fibroblasts; synaptic transmission; plasticity; neonatal rat; development; motor neuron; spinal cord

\section{Introduction}

Neurotrophins belong to a family of growth and trophic factors that function during development to promote axonal growth and neuronal survival (for review, see Mendell, 1995; Davies, 1996; Lindsay, 1996). Neurotrophins and their receptors, both the lowaffinity receptor p75 and the high-affinity trk receptors, are observed in the PNS and CNS of adult animals (Lindsay, 1996). This observation has prompted investigators to examine their possible use in encouraging spinal cord repair after injury. Neurotrophins have been shown to enhance behavioral recovery in contusion models of spinal cord injury (Horner and Gage, 2000), possibly by enhancing neuronal survival (Giehl and Tetzlaff, 1996; Giehl et al., 2001), by promoting elongation of injured axons (Xu et al., 1995; Bregman et al., 1997; Grill et al., 1997; von Meyenburg et al., 1998), or by promoting sprouting of fibers spared by the injury onto partially denervated cells (Schnell et al., 1994; von Meyenburg et al., 1998).

Neurotrophins are also known to affect synaptic efficacy at both central and peripheral synapses (for review, see Mendell et

\footnotetext{
Received Dec. 18, 2002; revised July 31, 2003; accepted Aug. 5, 2003.

This work was supported by the Christopher Reeve Paralysis Foundation (L.M.M. and F.H.G.), by National Institutes of Health Grants 2 R01 NS 16996 and P01 NS39420 (L.M.M.), and by the New York State Spinal Cord Injury Foundation (V.L.A.). We thank Honeyleen Manuzon from State University of New York at Stony Brook for assistance

Correspondence should be addressed to Dr. Lorne M. Mendell, Department of Neurobiology and Behavior, State University of New York at Stony Brook, Life Sciences Building Room 550, Stony Brook, NY 11794-5230. E-mail: lorne.mendell@sunysb.edu.

Copyright $\odot 2003$ Society for Neuroscience $\quad 0270-6474 / 03 / 238706-07 \$ 15.00 / 0$
}

al., 2001). In spinal motoneurons, the action of neurotrophins NT-3 and BDNF on AMPA/kainate receptor-mediated responses requires that the test pathway elicit a measurable NMDA receptor (NMDAR)-mediated response (Arvanov et al., 2000; Arvanian and Mendell, 2001b). Because NMDAR responsiveness in motoneurons declines during the first postnatal week as a result of enhanced magnesium block (Arvanian and Mendell, 2001a), the effect of neurotrophins is restricted to this early postnatal period. Interestingly, the monosynaptic response elicited in motoneurons by the ventrolateral funiculus (VLF) has no NMDARmediated component throughout the postnatal period, and in support of the hypothesis that NT-3 action depends on functional NMDARs, NT-3 is unable to potentiate the associated AMPA/kainate receptor-mediated response (Arvanian and Mendell, 2001a).

These previous studies involved a brief application of neurotrophins, with their actions being investigated for several hours thereafter. Little is known of the synaptic effects after chronic application of neurotrophins, particularly whether they can be initiated or persist beyond the period of NMDAR loss. The extent to which chronic effects of neurotrophins depend on NMDAR responsiveness would be particularly relevant for understanding their actions when applied in adults after spinal injury.

Recently, fibroblasts genetically engineered to secrete neurotrophins have been shown to be effective vehicles for long-term neurotrophin delivery to the in vivo CNS (Horner and Gage, 2000). Here, we tested whether NT-3-secreting fibroblasts placed 
intrathecally can modify synaptic transmission in the neonatal rat spinal cord. Chronic intrathecal delivery of NT-3 beginning on postnatal day 2 (P2) enhanced AMPA/kainate-mediated synaptic responses from both afferent [dorsal root (DR)] and descending (VLF) pathways for up to $10 \mathrm{~d}$ (P12). This suggested an NMDAindependent mechanism, because the synaptic response elicited by VLF has no NMDAR-mediated component throughout this period. This conclusion assumes that NMDARs were not altered by chronic treatment with NT-3, which was confirmed by demonstrating no change in susceptibility to $\mathrm{Mg}^{2+}$ block, the major reason for a loss of NMDAR function over this period (Arvanian and Mendell, 2001a).

A preliminary account of this work has been presented in abstract form (Arvanian et al., 2001).

\section{Materials and Methods}

Administration of neurotrophins via implantation of fibroblasts expressing neurotrophins and intracellular recordings were performed in accordance with protocols approved by the Institutional Animal Care and Use Committee at State University of New York at Stony Brook.

Preparation of collagen plugs containing NT-3-secreting or $\beta$-galactosidase-secreting fibroblasts. Cultured rat fibroblast cells genetically engineered to produce NT-3 or $\beta$-galactosidase ( $\beta$-Gal) were suspended in $0.6 \%$ glucose-PBS to a final concentration of $0.4 \times 10^{6}$ cells/ $\mu \mathrm{l}$, and a volume of $\sim 2 \mu \mathrm{l}$ was inserted in collagen plugs, as described previously (Kawaja and Gage, 1992; McTigue et al., 1998).

Surgical procedures and implantation of fibroblasts. Two-day-old (P2) Sprague Dawley rats were anesthetized by hypothermia by placing them on a latex glove in contact with a bed of ice for $10 \mathrm{~min}$. Under a dissecting microscope, the skin and muscles overlying the cord at L1-L2 were separated and retracted, and the underlying spinal cord segment was exposed by removing vertebral bone and slitting the dural sheath. To minimize disruption of the VLF on the left side of the spinal cord, the integrity of which was crucial to the experiment, the collagen plug (shaped as a half cylinder $1 \mathrm{~mm}$ in diameter and $1.5 \mathrm{~mm}$ long) was placed flat side down directly onto the cut in the dura on the right side of the spinal cord and held loosely in place with durafilm (Codman-Schurtleff, Inc.). The muscle and skin were sutured in layers with 5-0 silk sutures. Finally, the skin was glued using Vetbond (3M Corp.) tissue adhesive, and the wound was covered with sesame oil to prevent rejection of the pup by the mother. Pups were kept warm and were returned to the mother when they became active.

Intracellular recording. After $6 \mathrm{hr}$ to $12 \mathrm{~d}$ of treatment, the rats were prepared for electrophysiological study. Two age groups were used: $2-5 \mathrm{~d}$ old (1WO) and 8-14 d old (2WO). Rats from both groups were anesthetized in halothane ( $10 \mathrm{ml}$ in 5 liter volume) and decapitated; the spinal cord was removed from the animal, and a section of the left hemicord (spanning segments from approximately $\mathrm{T} 1$ to S3) was pinned to a Sylgard-coated surface in the recording chamber and prepared for the in vitro intracellular recording procedure using methods described previously in detail (Arvanov et al., 2000). A chamber was superfused (10 $\mathrm{ml} / \mathrm{min}$ ) with artificial CSF containing (in $\mathrm{mm}$ ): $117 \mathrm{NaCl}, 4.7 \mathrm{KCl}, 2.5$ $\mathrm{CaCl}_{2}, 2.0 \mathrm{MgSO}_{4}, 25 \mathrm{NaHCO}_{3}, 1.2 \mathrm{NaH}_{2} \mathrm{PO}_{4}, 11$ dextrose, aerated with $95 \% \mathrm{O}_{2} / 5 \% \mathrm{CO}_{2}, \mathrm{pH} 7.4$, at $\left.30^{\circ} \mathrm{C}\right)$. The $\mathrm{L} 5 \mathrm{DR}$ and ventral root (VR) as well as the cut VLF (dissected from the spinal cord at T2) (Pinco and Lev Tov, 1994) were placed in suction electrodes with silver-silver chloride internal wires for stimulation. The same suction electrodes were used throughout these experiments to maintain the size of the stimulated VLF and DR as uniform as possible.

Intracellular recordings (microelectrodes $70-110 \mathrm{M} \Omega$, filled with $3 \mathrm{M}$ potassium acetate) were made in lumbar spinal motoneurons in the L5 segment contralateral to the implantation site. Motoneurons were identified by their antidromic response to VR stimulation. Motoneuron input resistance was estimated by passing current pulses (100 msec) through the intracellular recording electrode, as described previously (Fulton and Walton 1986; Arvanov et al., 2000). Ten stimuli of $50 \mu \mathrm{sec}$ duration were delivered separately to DR and VLF at an intensity to evoke

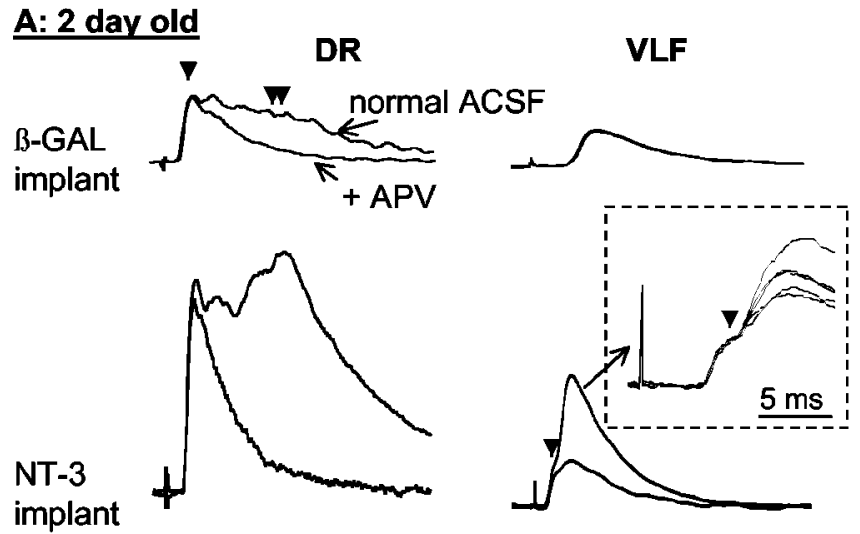

\section{B: 12 day old}
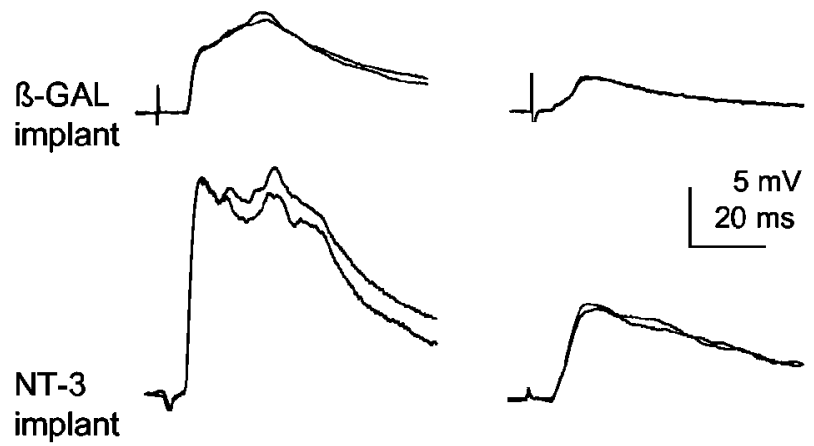

Figure 1. Synaptic responses to stimulation of DR and VLF $6 \mathrm{hr}$ ( $2 \mathrm{~d}$ old $)$ and $10 \mathrm{~d}$ ( $12 \mathrm{~d}$ old $)$ after implantation (at P2) with fibroblasts secreting NT-3 and $\beta$-Gal. Each row shows the averaged response of the same motoneuron to DR and VLF under one set of treatment conditions (e.g., $2 \mathrm{~d}$ old after treatment with $\beta$-Gal). The superimposed traces were evoked in "normal" artificial CSF (ACSF) and 20 min after bath administration of NMDAR antagonist D-APV $(40 \mu \mathrm{M})$. Monosynaptic and D-APV-sensitive components of DR-evoked EPSP were measured at single and double vertical arrows, respectively. Inset in dashed box shows superimposed single sweeps taken from the records making up the associated averaged VLF response. These are displayed on a faster time base to demonstrate the constant early response and fluctuating late response. Records of this sort were used to distinguish monosynaptic (constant amplitude, short latency) and polysynaptic responses (fluctuating amplitude, longer latency).

the maximum monosynaptic potential for DR $(\sim 100 \mu \mathrm{A})$ and to evoke the maximum response for VLF $(\sim 500 \mu \mathrm{A})$. The response of the motoneuron to these stimuli were averaged (pClamp 8; Axon Instruments; Fig. 1). The stimulation rate was $0.05 \mathrm{~Hz}$ but was lowered to $0.01 \mathrm{~Hz}$ when NMDAR-mediated responses were studied by blocking all the other responses pharmacologically (Fig. 2). Five-minute breaks were interspersed between groups of 10 stimuli in all experiments. Short latency responses were judged to be monosynaptic if they showed relatively little amplitude and latency fluctuation compared with later polysynaptic components when the responses to successive single trials were superimposed (Fig. 1, inset). These records were also used to estimate the onset of the polysynaptic potential.

To record the NMDAR-mediated synaptic responses, the AMPA/kainate receptor antagonist $10 \mu \mathrm{M}$ CNQX (Sigma, St. Louis, MO), GABA receptor antagonist $5 \mu \mathrm{M}$ bicuculline (Tocris, Ballwin, $\mathrm{MO}$ ), $\mathrm{GABA}_{\mathrm{B}}$ receptor antagonist $10 \mu \mathrm{M}$ CGP 35348 (Ciba Geigy, Basel, Switzerland) (Peshori et al., 1998) and glycine receptor antagonist $5 \mu \mathrm{M}$ strychnine (Sigma) were included in the perfusate, as described previously (Arvanian and Mendell, 2001a). In experiments with reduced concentrations of $\mathrm{Mg}^{2+}$ in saline, corresponding equiosmolar changes in $\mathrm{Na}^{+}$concentration were made.

The results are presented as mean \pm SEM. Except as noted, two-way ANOVA [treatment (NT-3; $\beta$-Gal) and duration (1 WO; 2WO)], followed by pairwise comparisons using post hoc Student-Newman-Keuls 
test adjusting for multiple comparisons (Sigmastat 2.0), was performed to analyze the significance of the differences.

Determination of NT-3 levels in the spinal cord using ELISA. Individual spinal cords were removed from the animal and rinsed in saline to completely remove the plugs. They were homogenized in a cell lysis buffer $(137 \mathrm{~mm}$ $\mathrm{NaCl} / 20 \mathrm{~mm}$ Tris-HCl, $\mathrm{pH}$ 8.0, containing $1 \%$ NP-40, 10\% glycerol, $1 \mathrm{~mm}$ PMSF, and $0.5 \mathrm{~mm}$ sodium vanadate) using polished glass pipettes. The concentration of crude protein was estimated using a BCA protein assay kit (Pierce, Rockford, IL). NT-3 concentration was assayed using an Emax ImmunoAssay System (Promega, Madison, WI). Briefly, 96-well plates were coated with anti-human NT-3 polyclonal antibody overnight, followed by the addition of triplicate $200 \mu \mathrm{g}$ protein samples from each spinal cord and a dilution series of recombinant NT-3 as a standard curve. Samples were incubated overnight at $4^{\circ} \mathrm{C}$, followed by application of a second anti-NT-3 monoclonal antibody. Anti-mouse IgG/HRP conjugate was added for $2 \mathrm{hr}$. Finally, all wells were incubated with tetramethylbenzidene for $15 \mathrm{~min}$ and measured spectroscopically for absorbance at $450 \mathrm{~nm}$. NT-3 concentration was calculated by plotting on the absorbance curve and was expressed as picograms of NT-3/milligram of protein.

\section{Results}

\section{Concentration of NT-3 in the} spinal cord

The concentration of NT-3 in cords treated with $\beta$-Gal-secreting fibroblasts averaged $68 \pm 20($ SEM $) \mathrm{pg} / \mathrm{mg}$ protein $(n=3)$. After treatment with NT-3-secreting fibroblasts, the concentration of NT-3 in the cord averaged $144 \pm 7 \mathrm{pg} / \mathrm{mg}$ protein $(n=3)$. These differences were significant (two-tailed $t$ test; $p<0.05$ ).

\section{DR- and VLF-evoked monosynaptic AMPA/kainate responses in motoneurons}

First, we compared the DR- and VLF-evoked EPSPs in motoneurons from spinal cords removed from $1 \mathrm{WO}$ and $2 \mathrm{WO}$ rats that had received implants of NT-3- or $\beta$-Gal-secreting fibroblasts at P2 (Fig. 1; Table 1). Stimulation of the DR is known to evoke an initial monosynaptic component mediated largely by CNQXsensitive AMPA/kainate receptors and a later polysynaptic component (Ziskind Conhaim, 1990; Thomas et al., 1998; Arvanov et al., 2000). Treatment with NT-3-secreting fibroblasts induced significant facilitation of the DR-evoked monosysynaptic responses independent of age compared with $\beta$-Gal treatment (Fig. 1 ; Table $1 ; p<0.001$ ), which had no significant effect as determined by comparison with DR-EPSPs in untreated preparations examined at the same age (Arvanian and Mendell, 2001a). This finding contrasts with the results of brief acute administration of NT-3, which facilitated monosynaptic DR-EPSPs in $1 \mathrm{WO}$ but not in 2WO animals (Arvanov et al., 2000). The loss of the ability of NT-3 to acutely enhance EPSP amplitude was associated with a decline in responsiveness of motoneuron NMDARs (Arvanian and Mendell, 2001a). The ability of chronic NT-3 to facilitate the monosynaptic DR-evoked EPSP in 2WO preparations suggests that at least the maintenance of the chronic NT-3 effect was independent of NMDARs (see Discussion). The late polysynaptic components of the DR responses were also elevated in prepara-

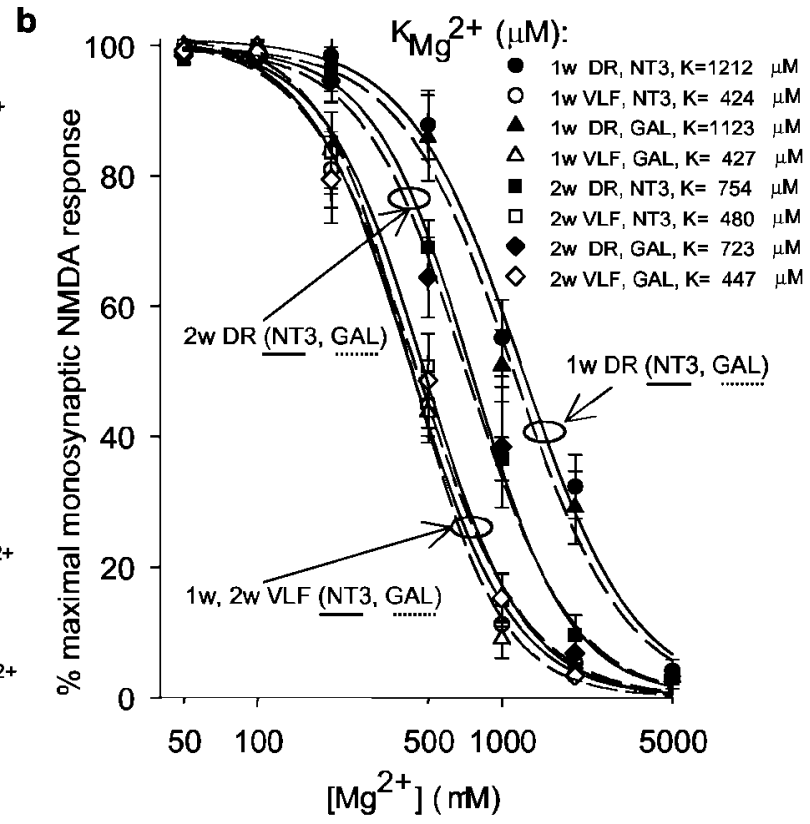

Figure 2. $\mathrm{Mg}^{2+}$ sensitivity of NMDA responses evoked in motoneurons of $1 \mathrm{~W} 0$ and $2 \mathrm{~W} 0$ animals by stimulation of DR and VLF fom animals implanted with fibroblasts secreting $\beta$-Gal or NT-3. $a$, Superimposed NMDAR-mediated responses evoked in difT2 2 with NT-3-secreting fibroblasts. These NMDAR-mediated responses were recorded in the presence of a mixture of nonparameter Hill equation. $K_{\mathrm{Mg}}$ is the dissociation constant for $\mathrm{Mg}^{2+}$ determined from this analysis. The oval shapes are drawn to ependence for NT-3-and $\beta$-Gal-treated preparations of a given age.

tions from rats implanted with NT-3-secreting fibroblasts (Fig. 1). However, we did not compare these polysynaptic components quantitatively because of the contribution of the falling phase of the monosynaptic EPSP, also affected by NT-3, to the later components of the response.

The VLF-evoked response is also CNQX sensitive and mediated by AMPA/kainate receptors throughout the first 2 postnatal weeks (Pinco and Lev Tov, 1994; Arvanov et al., 2000). These responses tended to have an initial rise time that was considerably longer than that of the DR (Fig. 1, responses), and we could observe the monosynaptic component reliably in only $\sim 60 \%$ of the cases under all experimental conditions used here. After treatment with NT-3, we noted a substantial increase in the magnitude of the peak response compared with treatment with $\beta$-Gal $(p<0.001$; Table 1$)$. The monosynaptic response was also enhanced by NT-3, independent of age ( $p<0.001$; Table 1$)$. Thus, chronic treatment with NT-3 enhanced the response from VLF, unlike acute treatment with NT-3 (Arvanian and Mendell, 2001a). This suggests that the chronic effects of NT-3 did not depend on the availability of NMDARs in the motoneuron. The mean latency of the response averaging over all preparations was diminished in NT-3-treated preparations, independent of age $(p<0.001$; Table 1$)$. This finding suggested an increase in VLF fiber conduction velocity as a result of chronic NT-3 treatment.

\section{$\mathrm{Mg}^{2+}$ block of NMDAR-mediated synaptic responses}

One possibility is that the function of NMDARs changed after chronic NT-3 treatment, such that they were now responsive at levels of $\mathrm{Mg}^{2+}$ used in these experiments, i.e., the expected decline in NMDAR-mediated responses caused by their increasing 
Table 1. Synaptic response of motoneurons to stimulation of DR and VLF after chronic treatment with NT-3 or $\beta$-Gal

\begin{tabular}{llll}
\hline & $\begin{array}{l}\text { Mean peak DR monosynaptic } \\
\text { response }(\mathrm{mV})\end{array}$ & $\begin{array}{l}\text { Mean peak VLF monosynaptic } \\
\text { response }(\mathrm{mV})\end{array}$ & $\begin{array}{l}\text { Mean peak VLF polysynaptic } \\
\text { response (mV) }\end{array}$ \\
\hline 1W0: $\beta$-Gal & $3.4 \pm 0.5(8)$ & $0.8 \pm 0.2(7)$ & $2.2 \pm 0.4(12)$ \\
1W0: NT-3 & $9.3 \pm 1.4(10)$ & $2.5 \pm 0.6(8)$ & $9.8 \pm 0.9(13)$ \\
2W0: $\beta$-Gal & $4.5 \pm 0.4(13)$ & $0.9 \pm 0.2(8)$ & $1.9 \pm 0.2(11)$ \\
2W0: NT-3 & $9.4 \pm 0.9(20)$ & $4.0 \pm 1.2(4)$ & $7.5 \pm 0.5(12)$ \\
\hline
\end{tabular}

DR monosynaptic response (column 1) increased after treatment with NT-3 in both 1 WO (row 2 vs row 1 ) and 2 WO (row 4 vs row 3) animals. Monosynaptic response could be measured for VLF stimulation in some cases (column 2), and the peak polysynaptic response (occurring 11-17 msec after the stimulus) was determined in all cases (column 3). Note the increase in both the mean monosynaptic and polysynaptic response in 1 W0 and 2 WO rats treated intrathecally with NT-3-expressing fibroblasts compared with those treated with $\beta$-Gal-expressing fibroblasts. Note also the decrease in latency of the response to VLF (column 4) after NT-3. Not all cells could be tested with both DR and VLF stimulation because of an inability to hold the cell sufficiently long or because of damage to one of the nerve bundles. The number of recorded cells is in parentheses. See Results for further details.

susceptibility to $\mathrm{Mg}^{2+}$ block (Kirson et al., 1999; Mendell and Arvanian, 2001) might have been reversed or delayed. If true, we would have to continue to consider NMDARs as possibly involved in the chronic effects of NT-3. To evaluate this, we determined whether the susceptibility of NMDARs to blockade by $\mathrm{Mg}^{2+}$ was altered after chronic treatment with NT-3.

To isolate the NMDAR-mediated response, all other known inputs to the motoneuron were blocked pharmacologically, and the monosynaptic NMDAR-mediated response evoked by stimulation of either the DR or the VLF was measured in different extracellular $\left[\mathrm{Mg}^{2+}\right]$, as described previously (Arvanian and Mendell, 2001a; Mendell and Arvanian, 2001). In a solution containing $50 \mu \mathrm{M}\left[\mathrm{Mg}^{2+}\right]$, the peak amplitude of the monosynaptic response (Fig. 2, arrow) in response to DR and VLF stimulation in chronic NT-3- and $\beta$-Gal-treated rats of both age groups was maximal (Fig. 2a). However, whether the cord had been treated with NT-3 or $\beta$-Gal, the $\mathrm{Mg}^{2+}$-induced decline of the NMDARmediated VLF response began at lower $\mathrm{Mg}^{2+}$ concentrations than the decline in the NMDAR-mediated DR response elicited in the same motoneuron (Fig. 2b). More importantly, for the present discussion, for each input (DR or VLF) and for each time point (1WO or 2WO), the value of the calculated dissociation constant (Chen and Huang, 1992) for $\mathrm{Mg}^{2+}$ block $\left(K_{\mathrm{Mg}}\right)$ was virtually identical for NT-3- and $\beta$-Gal-treated cords (Fig. $2 b$, compare grouped dissociation curves). These results indicate that treatment of rats with NT-3-secreting fibroblasts does not alter the $\mathrm{Mg}^{2+}$ sensitivity of NMDARs in motoneurons, despite large changes in response amplitude.

\section{Susceptibility of DR- and VLF-elicited responses to APV}

The responses elicited by DR and VLF are affected differently by the selective NMDAR antagonist APV in the untreated neonatal spinal cord during the first 2 postnatal weeks (Arvanov et al., 2000). During the first postnatal week, the polysynaptic DRevoked responses are diminished by APV but the monosynaptic one is affected only to a small extent $(<10 \%)$ in some preparations. In the second week, APV does not affect DR-evoked responses. The VLF-elicited response in untreated controls is never altered by treatment with APV throughout the first 2 postnatal weeks.

As shown in Figure 1, the monosynaptic DR response remained insensitive to APV despite the presence of the NT-3 implant, suggesting no development of NMDAR-mediated activity in association with this input. Therefore, we focused on the susceptibility of the DR and VLF polysynaptic responses (peak polysynaptic response observed 11-17 msec after the stimulus) to APV after chronic NT-3 and $\beta$-Gal treatment. We compared the effects of APV under these conditions with those after acute NT-3 treatments (using responses taken from the data of Arvanov et al., 2000). The polysynaptic component of the enlarged DR-EPSPs was significantly more sensitive to APV in $1 \mathrm{WO}$ than in $2 \mathrm{WO}$

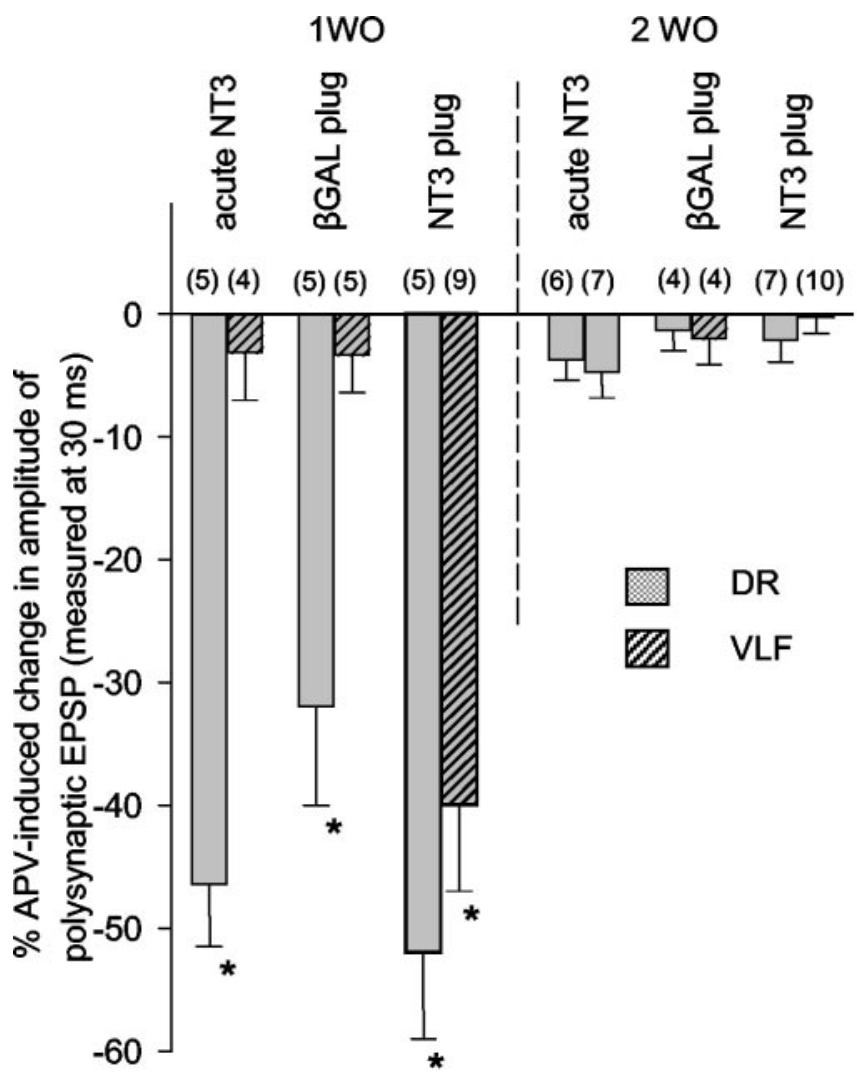

Figure 3. Effect of APV on polysynaptic potentials elicited by DR (stippled bars) and VLF (diagonal striped bars) in 1W0 (left of dashed line) and 2W0 (right of dashed line) rats after treatment with acute NT-3, with fibroblasts that release $\beta$-Gal, and with fibroblasts that release NT-3. Note the novel effect of APV on VLF responses in 1 WO rats treated chronically with NT-3 and the lack of effect of APV under any conditions in $2 \mathrm{~W} 0$ preparations. Numbers in parentheses indicate the number of cells whose responses were averaged for observation. Additional details are in Results.

preparations under all conditions (acute, chronic NT-3/chronic $\beta$-Gal; Fig. $3 ; p<0.001)$. Thus, chronic treatment with NT-3 did not result in a greater sensitivity of the DR polysynaptic response to APV than was observed in controls (acute treatment with NT-3 or treatment with $\beta$-Gal). In contrast, APV inhibited the VLF-evoked response in 1WO preparations treated with NT-3 plugs, an effect that was never seen in the other 1WO preparations (acute NT-3; chronic $\beta$-Gal) or in any $2 \mathrm{WO}$ preparations (Fig. 3).

Passive properties of motoneurons (membrane potential and input resistance)

Treatment with NT-3 secreting from fibroblasts produced no significant action on the membrane potential $[-64.4 \pm 1.5 \mathrm{mV}$ 
$(n=30)$ in NT-3 implants vs $-62.3 \pm 1.3 \mathrm{mV}(n=21)$ in $\beta$-Gal implants; $p=0.34$ ] or input resistance [31.5 $\pm 3 \mathrm{M} \Omega(n=7)$ in NT-3 implants vs $39.4 \pm 2.8 \mathrm{M} \Omega(n=6)$ in $\beta$-Gal implants; $p=$ 0.29 ] of the motoneurons. These results indicate that NT-3 secreted from the fibroblasts does not alter the passive properties of motoneuron membrane. This finding suggests that mechanisms other than the changes in membrane potential and input resistance trigger the chronic NT-3-induced facilitation of AMPA/ kainate-mediated synaptic transmission at both segmental and descending connections.

\section{Discussion}

Fibroblasts engineered to produce BDNF and NT-3 and placed intrathecally have been shown previously to improve recovery from spinal injury in adult rats. The criteria for recovery were generally behavioral and anatomical (Grill et al., 1997; Menei et al., 1998), but it was difficult to relate any functional recovery to specific cellular processes (Horner and Gage, 2000). In the present study, we used electrophysiological methods to study the strength of specific neuronal projections to motoneurons in intact neonatal rats and found highly specific increases in functional projections after chronic treatment with NT-3; these increases were not observed in controls in which the fibroblasts were engineered to produce $\beta$-Gal.

Previous reports have indicated that chronic systemic exposure to NT-3 strengthens the monosynaptic DR projection to motoneurons in neonatal rats (Seebach et al., 1999). Because the blood-brain barrier is not mature in these young animals (Tonra and Mendell, 1997), the locus of the change could not be established accurately. The present study extends these earlier results by demonstrating that monosynaptic DR projections are strengthened after chronic intrathecal administration of NT-3. A novel and significant conclusion is that these changes are not restricted to projections from the DR, because the VLF input to motoneurons is also increased. This finding differs strikingly from the observations made after direct application of NT-3 to the isolated spinal cord taken from neonates, in which the DR input was potentiated within minutes but the VLF input was not (Arvanov et al., 2000). Our data indicate that much of the increase in VLF input is caused by strengthening of polysynaptic pathways, but we did observe some increase in the monosynaptic projection after chronic treatment with NT-3.

NT-3 has previously been shown to acutely enhance transmission to motoneurons in neonatal rats (Arvanov et al., 2000). This potentiation requires that the pathway exhibiting elevated transmission activate functional NMDARs in the motoneuron (Arvanian and Mendell, 2001a). However, in the present experiments, chronically applied NT-3 enhanced monosynaptic transmission to motoneurons (Table 1) at connections that do not normally activate functioning NMDARs, i.e., the connections made by fibers in the VLF on motoneurons in 1WO preparations (Arvanian and Mendell, 2001a). This suggests that NMDARs are not required to initiate the potentiation of transmission triggered by chronically applied NT-3. These data also indicate that the maintenance of synaptic potentiation after chronic NT-3 is not dependent on the availability of functional NMDARs, a finding we have also noted for the potentiation after brief treatment with NT-3 (Arvanov et al., 2000).

In considering possible differences between acute and chronic effects of NT-3 it is important to consider the possibility that chronic application might have activated other members of the trk receptor family. NT-3 has been shown to be equally potent in activating trkA as NGF when they are chronically applied al- though it has only 1/10 the potency when applied acutely (Belliveau et al., 1997). However, although both large diameter (group I) sensory afferents and descending bulbospinal axons express trkC, neither expresses trkA (McMahon et al., 1994; King et al., 1999). This suggests that chronic NT-3 effects were exerted largely via the trkC receptor.

We investigated the possibility that chronic NT-3 had altered the NMDARs in motoneurons to make them more responsive at levels of $\mathrm{Mg}^{2+}$ used in the electrophysiologcal experiments, i.e., that VLF now could elicit NMDAR-mediated responses in postnatal preparations. We found no change in the susceptibility to $\mathrm{Mg}^{2+}$ block (Fig. 2). These findings support our conclusion that chronically delivered NT-3 potentiates transmission via mechanisms different from those operating acutely after NT-3 administration, specifically in not involving NMDARs. One possibility is that chronically applied NT-3 may enhance myelination of spinal axons, as shown previously with similar NT-3 treatments (McTigue et al., 1998). This would permit impulses to invade branching axon terminals more fully to activate the existing AMPA receptors more completely.

In additional experiments, we demonstrated that chronic treatment with NT-3 did not alter the susceptibility of DRevoked polysynaptic EPSPs to depression by APV (Fig. 3), i.e., no effect on these NMDAR-mediated components was observed. These NMDAR-mediated components were large in 1WO animals (substantial reduction by APV) and virtually nonexistent in 2WO animals, suggesting a distribution similar to that exhibited by the monosynaptic EPSP elicited by the DR (Arvanian and Mendell, 2001a). However, there was a substantial change in the VLF-elicited EPSP in the presence of chronic NT-3, specifically the appearance of a novel APV-sensitive polysynaptic component in $1 \mathrm{WO}$ animals that disappeared in the $2 \mathrm{WO}$ animals. Because these are polysynaptic potentials, we cannot determine the site of the responsible NMDAR. It might be at the synapse made by interneurons activated by VLF on motoneurons, although the monosynaptic component of these responses exhibited no increase in sensitivity to APV (Fig. 1). Another possibility is at VLF synapses on interneurons in segments close to the site of the NT-3-expressing fibroblasts (L1). These connections, which could contribute to the polysynaptic activation of motoneurons by VLF, might exhibit temporarily enhanced NMDAR efficacy.

Numerous lines of investigation now indicate a potentially important role for NT-3 in regulating the strength of synaptic connections on motoneurons. During the immediate postnatal stage, when connections are strengthening (Seebach and Mendell, 1996), NT-3 is available in motoneurons either from local synthesis or transport from other sources (Buck et al., 2000). Both sensory (McMahon et al., 1994) and descending axons (King et al., 1999) terminating on motoneurons express trkC receptors. The provision of excess NT-3 strengthens connections made by both of these projections (present findings), and diminishing NT-3 levels using the immunoadhesin trkC-IgG reduces the strength of the DR projection to some extent (Seebach et al., 1999). Together, these findings indicate that NT-3 is important in regulating the strength of connections to motoneurons during development.

In adult cats, chronic provision of NT-3 to the central cut end of the axotomized medial gastrocnemius via osmotic minipump reversed the axotomy-induced reduction in EPSP amplitude elicited by these spindle afferent fibers in intact, heteronymous lateral gastrocnemius-soleus motoneurons (Mendell et al., 1999). The increase in EPSP amplitude was substantial, much greater than the magnitude of the decrease associated with axotomy. It 
seems likely that an enhanced number of functional group Ia afferent terminals is partly responsible, because individual afferents projected to a higher fraction of the heteronymous motoneuron pool. Furthermore, the decrease in conduction velocity of the afferent fibers associated with their axotomy was also reversed, indicating an effect of NT-3 on the afferent fibers consistent with growth. These changes are consistent with the enhanced synaptic efficacy and reduced synaptic latency observed in the present experiments, possibly as a result of enhanced axon myelination (McTigue et al., 1998). However, the reduction in latency of the VLF response should be interpreted with caution, given the uncertainty in synaptic linkage between the stimulated VLF fibers and the recorded motoneurons in cases in which the response was not monosynaptic and the assumption of equal conduction distance for the different preparations in each age group.

Despite the similarities in the effects of NT-3 in these diverse experiments, it is important to keep in mind that the affected fibers were in very different states or were subjected to different forms of damage. In the case of afferent fibers in adult cats, the peripheral branch was cut and treated with NT-3, and the projection of the spinal branch was found to be strengthened. In the present experiments, the fibers were intact but possibly still in a growth mode. In the case of spinal cord injury in adult rats, spinal axons have variable pathology: either they regenerate from a point of damage at the contusion site or they are undamaged and undergo sprouting of terminals.

The application of neurotrophins to the injured spinal cord in the adult rat (Grill et al., 1997; Menei et al., 1998; Liu et al., 1999) has often been performed with some additional prosthesis, such as a neonatal cord implant or other substrate designed to support axonal growth (Horner and Gage, 2000). In those experiments, the improvement in function was generally attributed to growth of axons through the region of injury. However, in contusion injuries, a rim of white matter often survives intact (Basso, 2000; Metz et al., 2000). Strengthening the connections from these surviving fibers to neurons in the distal stump could mediate some recovery of function, particularly if their potency were enhanced by the action of neurotrophins, as we have shown here for VLF projections. This enhanced action might be caused by a direct effect of NT-3 on surviving fibers, or perhaps indirectly by upregulating other growth factors to promote myelination and fiber growth (McTigue et al., 1998). Given the difficulty of promoting substantial regeneration of cut fibers as well as the daunting task of encouraging these fibers to form synaptic connections on the appropriate interneurons in the distal stump, enhancing the functional connectivity of surviving fibers could aid in recovery from the consequences of injuries where at least some of the white matter remains intact.

\section{References}

Arvanian VL, Mendell LM (2001a) Removal of NMDA receptor $\mathrm{Mg}(2+)$ block extends the action of NT-3 on synaptic transmission in neonatal rat motoneurons. J Neurophysiol 86:123-129.

Arvanian VL, Mendell LM (2001b) Acute modulation of synaptic transmission to motoneurons by BDNF in the neonatal rat spinal cord. Eur J Neurosci 14:1800-1808.

Arvanov VL, Seebach BS, Mendell LM (2000) NT-3 evokes an LTP-like facilitation of AMPA/kainate receptor-mediated synaptic transmission in the neonatal rat spinal cord. J Neurophysiol 84:752-758.

Arvanov (Arvanian) VL, Horner PJ, Gage FH, Mendell LM (2001) Exposure of neonatal rat spinal cord to genetically engineered NT-3-secreting fibroblasts strengthens descending and afferent synptic connections in motoneurons. Soc Neurosci Abstr 27:905.13.

Basso DM (2000) Neuroanatomical substrates of functional recovery after experimental spinal cord injury: implications of basic science research for human spinal cord injury. Phys Ther 80:808-817.

Belliveau DJ, Krivko I, Kohn J, Lachance C, Pozniak C, Rusakov D, Kaplan D, Miller FD (1997) NGF and neurotrophin-3 both activate TrkA on sympathetic neurons but differentially regulate survival and neuritogenesis. J Cell Biol 136:375-388.

Bregman BS, McAtee M, Dai HN, Kuhn PL (1997) Neurotrophic factors increase axonal growth after spinal cord injury and transplantation in the adult rat. Exp Neurol 148:475-494.

Buck CR, Seburn KL, Cope TC (2000) Neurotrophin expression by spinal motoneurons in adult and developing rats. J Comp Neurol 416:309-318.

Chen L, Huang LY (1992) Protein kinase C reduces $\mathrm{Mg}^{2+}$ block of NMDAreceptor channels as a mechanism of modulation. Nature 356:521-523.

Davies AM (1996) The neurotrophic hypothesis: where does it stand? Philos Trans R Soc Lond B Biol Sci 351:389-394.

Fulton BP, Walton K (1986) Electrophysiological properties of neonatal rat motoneurones studied in vitro. J Physiol (Lond) 370:651-678.

Giehl KM, Tetzlaff W (1996) BDNF and NT-3, but not NGF, prevent axotomy-induced death of rat corticospinal neurons in vivo. Eur J Neurosci 8:1167-1175.

Giehl KM, Rohrig S, Bonatz H, Gutjahr M, Leiner B, Bartke I, Yan Q, Reichardt LF, Backus C, Welcher AA, Dethleffsen K, Mestres P, Meyer M (2001) Endogenous brain-derived neurotrophic factor and neurotrophin-3 antagonistically regulate survival of axotomized corticospinal neurons in vivo. J Neurosci 21:3492-3502.

Grill R, Murai K, Blesch A, Gage FH, Tuszynski MH (1997) Cellular delivery of neurotrophin-3 promotes corticospinal axonal growth and partial functional recovery after spinal cord injury. J Neurosci 17:5560-5572.

Horner PJ, Gage FH (2000) Regenerating the damaged central nervous system. Nature 407:963-970.

Kawaja MD, Gage FH (1992) Morphological and neurochemical features of cultured primary skin fibroblasts of Fischer 344 rats following striatal implantation. J Comp Neurol 317:102-116.

King VR, Michael GJ, Joshi RK, Priestley JV (1999) trkA, trkB, and trkC messenger RNA expression by bulbospinal cells of the rat. Neuroscience 92:935-944.

Kirson ED, Schirra C, Konnerth A, Yaari Y (1999) Early postnatal switch in magnesium sensitivity of NMDA receptors in rat CA1 pyramidal cells. J Physiol (Lond) 15:99-111.

Lindsay RM (1996) Role of neurotrophins and trk receptors in the development and maintenance of sensory neurons: an overview. Philos Trans R Soc Lond B Biol Sci 1996 351:365-373.

Liu Y, Himes BT, Solowska J, Moul J, Chow SY, Park KI, Tessler A, Murray M, Snyder EY, Fischer I (1999) Intraspinal delivery of neurotrophin-3 using neural stem cells genetically modified by recombinant retrovirus. Exp Neurol 158:9-26.

McMahon SB, Armanini MP, Ling LH, Phillips HS (1994) Expression and coexpression of Trk receptors in subpopulations of adult primary sensory neurons projecting to identified peripheral targets. Neuron 12:1161-1171.

McTigue DM, Horner PJ, Stokes BT, Gage FH (1998) Neurotrophin-3 and brain-derived neurotrophic factor induce oligodendrocyte proliferation and myelination of regenerating axons in the contused adult rat spinal cord. J Neurosci 18:5354-5365.

Mendell LM (1995) Neurotrophic factors and the specification of neural function. The Neuroscientist 1:26-34.

Mendell LM, Arvanov (Arvanian) VL (2001) NMDA receptors in individual neonatal rat motoneurons exhibit different sensitivity to $\mathrm{Mg}^{2+}$. Soc Neurosci Abstr 27:262.13.

Mendell LM, Johnson RD, Munson JB (1999) Neurotrophin modulation of the monosynaptic reflex after peripheral nerve transection. J Neurosci 19:3162-3170.

Mendell LM, Munson JB, Arvanian VL (2001) Neurotrophins and synaptic plasticity in the mammalian spinal cord. J Physiol (Lond) 533:91-97.

Menei P, Montero-Menei C, Whittemore SR, Bunge RP, Bunge MB (1998) Schwann cells genetically modified to secrete human BDNF promote enhanced axonal regrowth across transected adult rat spinal cord. Eur J Neurosci 10:607-611.

Metz GA, Curt A, van de Meent H, Klusman I, Schwab ME, Dietz V (2000) Validation of the weight-drop contusion model in rats: a comparative study of human spinal cord injury. J Neurotrauma 17:1-17.

Peshori KR, Collins WF, Mendell LM (1998) EPSP amplitude modulation 
at the rat Ia-alpha motoneuron synapse: effects of GABAB receptor agonists and antagonists. J Neurophysiol 79:181-189.

Pinco M, Lev-Tov A (1994) Synaptic transmission between ventrolateral funiculus axons and lumbar motoneurones in the isolated spinal cord of the neonatal rat. J Neurophysiol 72:2406-2419.

Schnell L, Schneider R, Kolbeck R, Barde YA, Schwab ME (1994) Neurotrophin-3 enhances sprouting of corticospinal tract during development and after adult spinal cord lesion. Nature 367:170-173.

Seebach BS, Mendell LM (1996) Maturation in properties of motoneurons and their segmental input in the neonatal rat. J Neurophysiol 76:3875-3885.

Seebach BS, Arvanov V, Mendell LM (1999) Effects of BDNF and NT-3 on development of $\mathrm{Ia} /$ motoneuron functional connectivity in neonatal rats. J Neurophysiol 81:2398-2405.
Thomas NK, Hawkins LM, Miller JC, Troop HM, Roberts PJ, Jane DE (1998) Pharmacological differentiation of kainate receptors on neonatal rat spinal motoneurones and dorsal roots. Neuropharmacol 37:1223-1237.

Tonra JR, Mendell LM (1997) Rabbit IgG distribution in skin, spinal cord and DRG following systemic injection in rat. J Neuroimmunol 80:97-105.

von Meyenburg J, Brosamle C, Metz GA, Schwab ME (1998) Regeneration and sprouting of chronically injured corticospinal tract fibers in adult rats promoted by NT-3 and the mAb IN-1, which neutralizes myelinassociated neurite growth inhibitors. Exp Neurol 154:583-594.

Xu XM, Guenard V, Kleitman N, Aebischer P, Bunge MB (1995) A combination of BDNF and NT-3 promotes supraspinal axonal regeneration into Schwann cell grafts in adult rat thoracic spinal cord. Exp Neurol 134:261-272.

Ziskind-Conhaim L (1990) NMDA receptors mediate poly- and monosynaptic potentials in motoneurons of rat embryos. J Neurosci 10:125-135. 